\title{
A pequena família guineana: abordagem discursiva do continuísmo histórico num discurso pela independência
}

Beatriz Adriana Komavli de Sánchez (UERJ)

\section{Resumo}

O propósito deste trabalho é analisar o discurso oficial pela independência da Guiné Equatorial pronunciado por um mandatário espanhol, representante do ditador Francisco Franco, no 12 de outubro de 1968. Esse pronunciamento faz parte de uma pesquisa maior que se propõe a explicitar a noção de Hispanidade. O 12 de outubro, data da chegada de Cristóvão Colombo na América, conhecida como 'descoberta' da América, foi justamente escolhido pelas autoridades guineanas daquele momento para comemorar a independência da jovem nação africana. A essa peculiaridade soma-se o fato da Guiné Equatorial ser a única nação africana que tem como língua maioritária oficial o espanhol. Guiados pela visão dialógica bakthiniana, adotamos como marco teórico a Análise do Discurso (AD) que considera os estudos enunciativos. Observamos uma rede de filiações identitárias que se tecem entre a Mãe pátria e a ex-colônia africana. A instância subjetiva que se manifesta num tom de exaltação está em consonância com um continuísmo histórico no que diz respeito à língua espanhola e a valores morais perpassados pela religião cristã. Isso se faz patente sobre tudo na reescritura do processo da colonização espanhola.

Palavras-chave: pequena família; independência; Guiné Equatorial; Análise do Discurso; Hispanidade. 


\section{Introdução}

Este trabalho tem como objetivo analisar um documento histórico, o discurso oficial de 12 de outubro de 1968 pronunciado pela independência da Guiné Equatorial. Esse pronunciamento faz parte de uma pesquisa maior que se propõe a explicitar a noção de Hispanidade. Consideramos o discurso apresentado um achado no decorrer de nossa pesquisa historiográfica, não só no sentido de algo encontrado, resgatado da memória institucional, mas tambéme, sobretudo, pela conotação de riqueza, uma vez que à força da data da 'descoberta' da América soma-se o fato muito curioso, peculiar, de ter sido escolhida pelas próprias autoridades guineanas daquele momento justamente para proclamar a independência dessa nação africana. Além disso, esse tipo de discurso, com essas formações discursivas relativas à língua, à religião e aos valores morais nos pareceu de reaparição tardia uma vez que na América, a partir de 1950, esses pronunciamentos sofrem um apagamento frente ao avanço do multiculturalismo como movimento político. O interesse é redobrado na medida em que a Guiné Equatorial é a única nação africana que tem como língua majoritária oficial o espanhol, fato muito pouco conhecido até pelos próprios hispano-falantes e estudantes de língua espanhola como LE. Esclarecemos que além do espanhol são línguas oficiais o francês, em segundo lugar desde 1998, e o português, em terceiro, desde 20/07/2012. Ressaltamos que estas línguas são segundas em relação a outras nativas tais como o fang e o bubi, entre outros grupos étnicos. Por si só esses dados instigam o interesse de um estudo, mas em nosso caso as repercussões foram redobradas na medida em que nos levou a constatar regularidades e, como consequência do anterior, nos possibilitou repensar critérios de recorte de nossa investigação.

\section{Marco teórico}

Passamos, então, a expor algumas considerações sobre o dia festivo, comemorativo pelo 12 de outubro. Essa data vigente no calendário oficial espanhol e em muitos países hispanofalantes tem sido objeto de ressignificações ao longo do tempo. Esse fato, por si só, indica que o/s sentido/s tem/têm se deslocado. Os discursos pelo 'Dia da Raça', 'Dia da Hispanidade', vigoraram com força entre finais do século XIX e a primeira metade do século XX e respondem a circunstâncias históricas e políticas muito particulares. Esses discursos oficiais, pronunciados por presidentes ou altos mandatários do governo, tratavam de um âmbito não de objetos materiais senão de dependências simbólicas e de parentesco. Esse vínculo exaltado com a 'mãe pátria' foi tão relevante que se materializou não só em outros domínios associados, tais como nas políticas educativas e nos posicionamentos políticos das Academias de Língua e Letras da América de aquela época, 
como na criação de uma bandeira da raça, hinos e numa série de práticas sociais.

Atualmente, a construção de um arquivo com estes pronunciamentos se nos apresenta como uma tarefa instigante e desafiadora. Sua leitura, sua descrição hoje, provoca um efeito de raridade que, segundo Foucault ([1969]1995), faz com que pertençam a um espaço privilegiado, "entre a tradição e o esquecimento", uma vez que o regime de enunciabilidade tem mudado:

A análise do arquivo comporta, pois, uma região privilegiada: ao mesmo tempo próxima de nós, mas diferente de nossa atualidade, trata-se da orla do tempo que cerca nosso presente, que o domina e que o indica em sua alteridade; é aquilo que fora de nós, nos delimita. A descrição do arquivo desenvolve suas possibilidades (e o controle de suas possibilidades) a partir dos discursos que começam a deixar de ser os nossos. (idem, p. 150-151)

A visão dialógica de Bakthin e a Análise do Discurso de linha francesa que considera os estudos enunciativos ajudarão a destacar algumas marcas linguísticas da rede de filiações identitárias que se teciam entre a Espanha e as ex-colônias materializadas nos discursos oficiais pelo 12 de outubro. (2000):

O gênero pronunciamento é assim caracterizado por Daher

No gênero pronunciamento político, o enunciador costuma anunciar de forma explícita a quem se dirige, embora possa dirigir-se a muitos outros destinatários que não os diretamente anunciados, valendo-se de outros recursos. Estes direcionamentos podem ser recuperados nos discursos por meio de diferentes marcas linguísticas.

Outra particularidade desse discurso político presidencial é a de que o enunciador tem garantido pelo poder do cargo empírico que ocupa o direito ao pronunciamento - já que seu papel social assim o autoriza e legitima. A certeza de um auditório no qual se incluem não só os destinatários explicitamente designados por ele em seu discurso, mas uma multiplicidade de "ouvintes" é outra marca importante desses discursos. (DAHER, 2000, p. 86)

Foucault, em sua arqueologia, afirma que os limites do enunciado são os outros enunciados com os quais se pode estabelecer um espaço de correlações, na medida em que tratam do mesmo domínio de objetos, e mais ainda: "não há enunciado que, de uma forma ou de outra, não reatualize outros enunciados" ([1969]1995, p. 113). Essa relação não só é possível de ser estabelecida com outros enunciados passados como também condiciona, inaugura, um leque de relações possíveis futuras. Aqueles enunciados renegados são reformulados por Maingueneau (2008, p. 37) em termos de 'interdito' de um discurso, do 'dizível faltoso'. Esses vínculos conformam um jogo enunciativo que é preciso examinar. 
Nesta aproximação destacamos o processo designativo que conforma, desenha objetos de discurso. Esse processo compreende estratégias de substituição, de paráfrases, de sinonímia, etc, criando, por um lado, a ilusão de uma equivalência entre as palavras e, por outro, a estabilização do referente. Esse processo funciona simultaneamente descrevendo e qualificando. Orlandi (apud KARIM, 2001, p. 83-108) refere-se a dito mecanismo em termos de reescritura. Para a autora, a reescritura é um mecanismo constitutivo da linguagem que nos possibilita nomear algo ou alguém de modos diferentes, parafraseando-o. Do conflito, da tensão que subjaz entre a paráfrase (o mesmo) e a polissemia (o diferente), surge o sentido como efeito.

Para melhor entender e contextualizar nossa aproximação ao processo de descolonização africana, recorremos aos aportes de Anderson ([1983] 2011), obrigatórios para compreender o surgimento de uma nação. Em sua clássica obra de referência para os estudiosos das ciências sociais, Anderson (idem, p. 32) assim define o conceito de nação, guiado por uma visão antropológica: "uma comunidade política imaginada - e imaginada como sendo intrinsecamente limitada e, ao mesmo tempo, soberana". "Imagina-se" e não "inventa-se", uma espécie de fraternidade horizontal que atravessa todos os integrantes que, sem se conhecerem, conformam esse conceito moderno aglutinante que se materializa em práticas.

Anderson, no capítulo 6, intitulado 'A última onda', aborda de maneira geral o surgimento das nações nos territórios coloniais na África e na Ásia. Afirma que nos novos estados da segunda pós-guerra "um enorme número dessas nações veio a ter línguas oficiais europeias, ...herança do nacionalismo oficial imperialista" (p. 164-5). O autor afirma que a criação e difusão de instituições de ensino possibilitou a formação de quadros de funcionários e intelectuais bilíngues que seriam os dirigentes das novas nações. Aventuramo-nos a pensar que nesse aspecto a jovem Guiné não foi exceção nessa 'última onda' de surgimento de nações.

Uma festa compartilhada pode cumprir a função de afiançar, também, laços culturais. A propósito das festas nacionais, Tateishi (2005, p. s/d) aponta dois tipos de celebrações da memória pública: "a que insiste na continuidade da nação desde o passado histórico, e a que celebra a nação moderna a partir da ruptura com o passado".

Conflitos internos na Espanha adiaram a definição de uma data comemorativa nacional até que as celebrações pelo IV Centenário da Descoberta da América em 1892, logo a perda em 1895 de Cuba e de Porto Rico em 1898, o crescente expansionismo dos Estados Unidos na América, a tentativa fracassada no norte da África e os regionalismos internos aceleraram a necessidade de reatar laços com as ex-colônias americanas, agora estimadas como 'filhas' sob um novo prisma da política externa, cujo pro- 
pósito era recuperar um prestígio perdido. Para isso, seguindo a Tateishi (2005), a mãe pátria recorre a seu passado exaltando-o. A coincidência da data com o dia festivo religioso da Virgen del Pilar, aliada à ideologia dessa hispanidade, mostrou-se muito eficaz para consolidar a data comemorativa: "trata-se assim de pôr de manifesto a pureza moral da nacionalidade espanhola: a categoria superior, universalista, de nosso espírito imperial, da Hispanidade, (...) defensora y missioneira da verdadeira civilização, que é a Cristiandade" (VALLS, 1999 y ABÓS, 2003, apud TATEISHI, 2005 , p. s/d). No entanto, a festividade só ganha estatuto legal no 9 de janeiro de 1958. Segundo o mencionado autor, a festa do 12 de outubro na Espanha não se encaixaria em nenhum dos dois tipos apontados no parágrafo anterior. Nesse sentido é coincidente com Juliá (1990) que, em seu artigo jornalístico Vieja nación, fiesta imperial, assim qualifica esta comemoração "festa impossível da nação espanhola".

Se é imperial, se é impossível para Espanha, como qualificá-la para as ex-colônias? Na América, a proposta, feita pela União Ibero-Americana em 1912, de adotar a data do 12 de outubro como Dia da Raça foi rapidamente acolhida por muitos governos. Na Venezuela, o presidente Hugo Chávez, a partir da organização política das comunidades indígenas, pelo decreto $\mathrm{n}^{\circ} 2028$ de 10 de outubro de 2002, rebatiza a data que atualmente celebra o Dia da resistência Indígena. Mais próximo temos o decreto 1584/2010 sobre feriados nacionais e dias não laboráveis da atual presidente argentina, Cristina Kirchner, quem assim redesigna a data: Dia do Respeito à Diversidade Cultural. Como qualificá-la quando essa data que celebra também um outrora império é escolhida por dirigentes da nascente nação africana para celebrar a independência, justamente a ruptura com um passado? Não restam muitas opções; trata-se, então, de celebrar um continuísmo.

Para entender esses deslocamentos de sentido é mister considerar que até a metade do século XX predominou uma maneira única, monolítica, de entender a unidade cultural de cada nação que dá lugar, na segunda metade desse século, ao multiculturalismo. Heymann (2007, p. 16-17) aponta que, em escala mundial, esse processo foi motivado: pela desagregação da União Soviética, pela descolonização da África, pela constituição de novos blocos econômicos (UE e Mercosul), pelo processo de globalização e pelos movimentos migratórios. Grupos inteiros que tinham permanecido no esquecimento, neste caso os descendentes que restaram das diversas comunidades indígenas, lutaram pelos seus direitos e reivindicaram seu lugar na memória agora transformada em valor, um dever moral de reconhecer múltiplas identidades, tal como aponta Heymann (2007). Consideramos então que é esse novo regime de enunciabilidade que nos possibilitará a descrição discursiva. 


\section{Contextualização do discurso}

É indispensável fazer um percurso histórico, nem que seja sucinto, para melhor entender as condições de produção do pronunciamento objeto deste trabalho. Com essa finalidade destacamos alguns fatos relevantes que foram pesquisados pela internet, já que nos defrontamos com a inexistência de obras ou artigos sobre a história da Guiné Equatorial em importantes bibliotecas universitárias. Esse apagamento da história é muito significativo.

Durante a segunda metade do século XV o território da atual Guiné Equatorial foi objeto de interesse da Coroa Portuguesa para o comércio de escravos. Em 1777 Espanha e Portugal assinam o Tratado de São Ildefonso pelo qual passa a ser possessão espanhola. Em 1827 Espanha autoriza a exploração para a Coroa Britânica. Em 1861 para colonizar e retomar o controle, Espanha envia pela força um contingente de cubanos. Logo após a perda de Cuba em 1895 e de Porto Rico em 1898, últimos bastiões do poderio espanhol, cresce o interesse pelo território africano. $\mathrm{Na}$ Conferência de Berlim realizada em 1888, as nações imperiais europeias repartem o território e a fatia que corresponde a Espanha diminui. Essa redução acentua-se com o Tratado de Paris em 1900. Durante a Primeira Guerra Mundial e a Guerra Civil Espanhola cresce o interesse colonizador, são criadas instituições educativas e há investimento sanitário. Um ministro espanhol visita pela primeira vez a colônia em 1948, agora rentável pela produção e exportação de café e de madeiras. O primeiro movimento insurgente Monalige (Movimento de Liberação da Guiné) tem aparição em 1952. Em 1959 a colônia passa a ser considerada uma região espanhola e a população passa a ter os mesmos direitos que os colonos. Quatro anos após ganha o status de autonomia. Todas essas bondades não foram suficientes e as Nações Unidas continuaram pressionando para fixar uma data para a libertação do território guineano. Em 1967 uma conferência institui-se no intuito de criar uma Constituição. A partir dela há liberdade para a criação de partidos políticos e livre expressão de ideias, fato curioso, pois esses eram diferenciais com relação ao território espanhol daquela época, sob o poderio franquista. Das primeiras eleições surge Francisco Macías Nguema como presidente, fruto de uma coligação governamental. Foram as próprias autoridades que escolheram a data do 12 de outubro para celebrar a sua independência. Logo após, a jovem nação independente passa por um período negro, coincidente com a época das ditaduras sofridas em vários países. Macías se adjudica plenos poderes, suspende

Página oficial do Governo da República da Guiné Equatorial: http://www.guineaecuatorialpress.com/ Consulta realizada em 15/11/2012. a constituição de 68 , a população sofre com derramamento de sangue e terror, e até ordena a queima de bibliotecas, como nos velhos tempos do nazismo ${ }^{1}$.

O atual e segundo presidente da Guiné Equatorial é Teodoro Obiang Nguema Mbasogo, no poder desde 1979. A página oficial 
2 Dados obtidos de http://www.brasilescola.com/geografia/guine-equatorial. htm Consulta realizada em 16/11/2012.

3 Dada a extensão do discurso não o apresentamos em anexo. Remetemos o leitor a http:// es.wikisource.org/ wiki/Discurso_del_12_ de_octubre_de_1968_ por_la_independencia_ de_Guinea_Ecuatorial Consulta realizada em 06/04/2012.

4 (1) A prudência do Caudilho da Espanha; (2) Uma data histórica exemplar: 12 de outubro; (3) A independência da Guiné Equatorial, no marco da emancipação africana; (4) Problemas e esperanças da nova etapa; (5) A obra da Espanha na Guiné; (6) O início da descolonização; (7) A Guiné Equatorial não está sozinha; (8) Língua espanhola; (9) Harmonia racial; (10) Guiné independente e Espanha. do governo, logo embaixo da portaria, apresenta assim o país: Um país cujo desenvolvimento cresce dia a dia. O brasão de armas tem o lema Unidade, Paz, Justiça. É o país africano com maior PIB per capita e seu índice de desenvolvimento (IDH) é 0,538, ainda distribuído de forma muito desigual. Esse crescimento em grande parte se deve à produção e exportação de petróleo e gás desde $1990^{2}$.

\section{Aproximações ao discurso de 12 de outubro de 1968}

A sessão foi realizada no Salão do Trono do Palácio Presidencial em Santa Isabel de Fernando Poo, no dia 12 outubro de 1968. Foi pronunciado pelo representante do chefe do Estado Espanhol, Francisco Franco, o Ministro de Informação e Turismo, encarregado de Assuntos Exteriores, D. Manuel Fraga Iribarne, ante o presidente da República da Guiné Equatorial, D. Francisco Macías $^{3}$. Para nosso pesar, nossas buscas pelo discurso do primeiro presidente guiné-equatoriano foram infrutíferas.

O discurso divide-se em dez tópicos e tem uma extensão de sete páginas. Apresentamos os títulos desses tópicos numerados esclarecendo que a nossa tradução de todos os fragmentos citados se encontram nas notas finais: (1) La prudencia del Caudillo de España; (2) Una fecha histórica ejemplar: 12 de octubre; (3) La independencia de Guinea Ecuatorial, en el cuadro de la emancipación africana; (4) Problemas y esperanzas de la nueva etapa; (5) La obra de España en Guinea; (6) La puesta en marcha de la descolonización; (7) La Guinea Ecuatorial no está sola; (8) Lengua española; (9) Armonía racial; (10) Guinea independiente y España ${ }^{4}$.

Como em todo discurso, outras vozes comparecem de maneira mais ou menos explícita, direta ou indiretamente, para conformar sua malha. Apresentamos essas vozes seguidas de números entre parênteses que indicam a localização nos tópicos acima numerados. São estas as marcas de heterogeneidade discursiva: o então vice-presidente do governo espanhol, o Almirante Carrero Blanco (6); um lema ('o melhor índio é o índio morto'); um historiador (Toynbee) e o filósofo mexicano José Vasconcelos. Ressaltamos que essas três últimas vozes são trazidas no tópico (9) Harmonia racial. A título de interdiscurso são lembrados: duas sessões da Conferência Constitucional celebrada no Ministério de Assuntos Exteriores Espanhol, presididas por Fernando María Castiella; um referendum e duas eleições (6); as Nações Unidas e a Organização da Unidade Africana (7).

Chamaram em especial nossa atenção as designações relativas a Francisco Franco e à colonização espanhola. Apresentamos a seguir um levantamento não exaustivo do processo de reescritura desses e de outros objetos do discurso. Destacamos que no tópico (1) o Ministro Iribarne insta que se renda homenagem a Franco. Já a colonização espanhola é designada em outros termos. Em todo o discurso só há uma ocorrência da palavra descolonização no subtítulo (6). 
5 Francisco Franco: $A$ prudência do Caudilho da Espanha; Sua Excelência o Chefe do Estado espanhol. sua previsão; sua prudência; a altura de suas ambições e a firmeza de seus propósitos; o generalíssimo Franco, o homem clarividente e veraz; a decisiva parte; o artífice com vocês da prazerosa e esperançosa realidade (1); nosso Chefe de Estado (10).

6 A colonização da Guiné: uma obra (1); uma história que acaba; o início de uma longa e difícil empresa; a incorporação ao Cristianismo e à Civilização um vasto cenário geográfico e um enorme conjunto de povos dispares, uma "Política de Missão" (2); a obra providente da Espanha ao longo de quase dois séculos de vida em comum (4); A obra da Espanha na Guiné; sua presença nestas terras; nossos missionários; a doutrina redentora do Cristianismo; uma enorme força moral: a possibilidade de entrar num âmbito de ideias e de conceitos; o acesso ao mundo da civilização cultural e técnica; a primeira etapa-etapa fundacional e transcendental-da presença da Espanha na Guiné (5).

7 Espanha: o seio da Espanha (2); a cujos filhos (8).

8 A independência da Guiné: o nascimento de um novo Estado (1); outra história que começa; uma nova filha emancipada da tutela materna, uma nova nação independente (2). neste momento histórico, o berço desta nação que vai nascer (3); neste momento transcendental (4); a independência destas terras (6); a aparição de uma nação soberana cuja Constituição (8); uma nação independente, encarregada de realizar seu próprio destino; o Estado nascente; o momento da separação jurídica e política entre a Espanha e a República da Guiné Equatorial; o primeiro dia na história livre da Guiné Equatorial (10).

9 A língua espanhola: o vínculo mais forte; $a$ segunda do mundo pelo número de nações e de gentes que a cultivam $l i$ -
Francisco Franco: La prudencia del Caudillo de España; Su Excelencia el Jefe del Estado español; su previsión; su prudencia; la altura de sus miras y la firmeza de sus propósitos; el Generalísimo Franco, el hombre clarividente y veraz; la decisiva parte; el artífice con vosotros de la gozosa y esperanzadora realidad (1); nuestro Jefe del Estado (10) ${ }^{5}$.

A colonização da Guiné Equatorial: una obra (1); una historia que acaba; la iniciación de una larga y difícil empresa; la incorporación al Cristianismo y a la Civilización un vasto escenario geográfico y un enorme conjunto de pueblos dispares; una "Política de Misión" (2); la obra providente de España a lo largo de casi dos siglos de vida en común (4); La obra de España en Guinea; su presencia en estas tierras; nuestros misioneros; la doctrina redentora del Cristianismo; una enorme fuerza moral; la posibilidad de entrar en un ámbito de ideas y de conceptos; el acceso al mundo de la civilización cultural y técnica; la primera etapa -etapa fundacional y transcendental -de la presencia de España en Guinea (5)

Espanha: el seno de España (2); a cuyos hijos (8).

A independência da Guiné Equatorial: el nacimiento de un nuevo Estado (1); otra historia que comienza; una nueva hija emancipada de la tutela materna, una nueva nación independiente (2); en este momento histórico; la cuna de esta nación que va a nacer a la independencia (3); en este momento transcendental (4); la independencia de estas tierras (6); la aparición de una nación soberana cuya Constitución (8); una nación independiente, encargada de realizar su propio destino; el Estado naciente; el momento de la separación jurídica y política entre España y la República de Guinea Ecuatorial, el primer día en la historia libre de Guinea Ecuatorial (10)․․

A língua espanhola: el vínculo más fuerte; la segunda del mundo por el número de naciones y de gentes que la cultivan literaria $y$ coloquialmente; su segunda lengua de cultura; su lengua para la relación universal, la que les abre las puertas del mundo; el precioso legado de un idioma universal; un lazo; la lengua española como su idioma oficial $(8)^{9}$.

A grande família: una gran familia de pueblos, de distintas razas y en varios continentes, compañia segura y leal; esa gran familia, unida entre sí por lazos de comunidad y no de sociedad, historia común, el mismo Dios en el mismo idioma, de la vida idéntico sentido transcendente; los lazos de esta familia, lazos familiares; lazos flexibles, cambiantes en lo contingente, inconmovibles en la intimidad, de profunda identificación; en el seno de esta familia, que es una familia vuestra, entrañablemente acompañados; el día de la gran fiesta familiar, el Día de la Hispanidad (7); doscientos millones de hispanoparlantes $(8)^{10}$.

A pequena família: otra pequeña familia, una familia restringidísima que es la inmediatamente nuestra; nuestros dos pueblos; cuyos lazos; vuestra mejor compañía, unos estrechos lazos de amistad, de ayuda mutua, de relación constante $(10)^{11}$. 
Continuação notas 9 , 10 e 11.

terária e coloquialmente; sua segunda lingua de cultura; sua língua para a relação universal, a que abre as portas do mundo; o preciosos legado de um idioma universal; um laço; a língua espanhola como seu idioma oficial(8).

10 A grande família: uma grande família de povos, de distintas raças e em vários continentes, companhia segura e leal; essa grande família, unida entre si por laços de comunidade $e$ não de sociedade, história comum, o mesmo Deus no mesmo idioma, da vida idêntico sentido transcendente; os laços desta família, laços familiares; laços flexíveis, mutáveis no contingente, incomoviveis na intimidade, de profunda identificação; no seio desta família, que é uma família de vocês, intimamente acompanhados; o dia da grande festa familiar, o Dia da Hispanidade (7); duzentos milhões de hispanofalantes (8).

11 A pequena família: uma outra pequena família, uma família restringidíssima que é a imediatamente nossa; nossos dois povos; cujos laços; vossa melhor companhia; uns estreitos laços de amizade, de ajuda mútua, de relação constante (10).
Resolvemos designar o enunciador que depreendemos deste discurso como 'enunciador bom missionário', seguindo a lógica imperialista exposta, se a própria colonização só é designada e assumida em termos de uma política de missão, 'a obra' só está completa com a emancipação dos filhos que agora civilizados e cristãos não mais dependem da sua tutela. A tentativa renegadora é tão forte que só verificamos uma única ocorrência da palavra descolonização no subtítulo (6).

Nesse sentido nos chamou a atenção uma série de negativas que merecem um comentário na medida em que são condizentes com a tentativa de silenciar um passado imperial e, pelo signo religioso, transformá-lo numa obra missionária. Trata-se das seguintes negações polêmicas:

a) Porque Espanha não praticou jamais uma política misericordiosa, de exploração econômica, de manutenção do nativo no terror, na ignorância e na doença. (3)

Não há condições, não temos colocado a vossa independência o menor marco. (10)

c) Nem a Espanha nem os espanhóis sentiram-se nunca alheios, indiferentes ou superiores àqueles povos com os que conviveram e aos que incorporaram à civilização ocidental e cristã. (10)

Consideramos que (a) e (c) refutam argumentos contrários à colonização de detratores não identificados, enquanto (b) possivelmente responde tanto a pressões internas da Monalige quanto externas, exercidas pelas Nações Unidas e outras organizações africanas.

\section{Considerações finais}

As aproximações ao discurso de 12 de outubro de 1968 pela independência da Guiné Equatorial mostraram-se muito profícuas por vários motivos. Mais uma vez confirmamos que a noção de hispanidade que se depreende dessa materialidade linguística se afasta da definição ampla e vaga encontrada nos dicionários. Ao mesmo tempo verificamos a insistência da exaltação da língua espanhola e de valores morais sob o signo do cristianismo, sem distinção de continentes. Essas formações discursivas atravessaram mares e deixaram uma impronta nos territórios colonizados pela coroa espanhola.

Sob a visão espanhola daquela época, há uma grande família conformada por todas as nações cristãs, de língua espanhola e com idêntico sentido transcendente, um vínculo horizontal que superaria as fronteiras geográficas. Há também 'outra pequena família', esta pequena família é a guineana e é pequena porque aponta aos vínculos bilaterais entre a Espanha e a jovem nação africana. Além disso, repetimos, é a única no continente africano que tem o espanhol como língua oficial majoritária. É tão pequena que quase é invisível até para os próprios hispanofalantes, hispanistas e alunos de espanhol como língua estrangeira. 
Com este trabalho também confirmamos mais uma vez que a data de 12 de outubro serviu de cartaz político para a Espanha resgatar um prestígio internacional perdido. A hispanidade de finais do século XIX e da primeira metade do XX foi fortemente marcada pelo conservadorismo e na Espanha pelo nacional-catolicismo de Franco. Nesse sentido coincidem vários autores como Glozman (2008), González (2005) e Tateishi (2005).

Para finalizar apontamos que desde a segunda metade do século XX o multiculturalismo começa a se projetar como movimento político e esfarela e dessacraliza, por assim dizer, uma visão monolítica de língua e de cultura.

\begin{abstract}
The purpose of this work is to analyze the official speech given by a Spanish authority, representative of the dictator Francisco Franco, in October 12 of 1968, which was related to the independency of the Equatorial Guinea. This pronouncement is part of major research proposed to explicit the notion of Hispanicity. October the 12th, day of the arrival of Christopher Colombus in America, also known as the "discovery" of America, was chosen by Guinean authorities of the time to celebrate the independency of the new African nation. An additional peculiarity of the Equatorial Guinea is its uniqueness as the only African nation to have Spanish as the main official language. Guided by the dialogical bakthinian vision, we adopt as our theoretical standpoint the Discourse Analysis (DA), which takes into account enunciative studies. We observe a net of identity affiliations that is interweaved between the Mother Nation and the African ex-colony. The subjective instance that is manifested in an exaltation tone is in concordance with a historical continuism with respect to the Spanish language and the moral values steeped by the Christian religion. This is mostly observed in the rewriting of the process of Spanish colonization.
\end{abstract}

Keywords: small family; independency; Equatorial Guinea; Discourse Analysis; Hispanicity.

\title{
REFERÊNCIAS
}

ANDERSON, Benedict. Comunidades imaginadas: reflexões sobre a origem e a difusão do nacionalismo. Trad. Denise Bottman. $2^{\mathrm{a}}$ reimpressão. São Paulo: Companhia das Letras, 2011. 
DAHER, Maria C. F. G. Discursos presidenciais de $1^{\circ}$ de maio: a trajetória de uma prática discursiva. Tese de doutorado em Linguística Aplicada ao ensino de línguas. PUC-SP, 2000.

FOUCAULT, Michel. A Arqueologia do Saber. $4^{\mathrm{a}}$ ed. Rio de Janeiro: Forense Universitária, [1969]1995.

GLOZMAN, M. La Academia Argentina de Letras y el peronismo (1946-1956). Anclajes XIII, 2008, p. 129-144.

GONZÁLEZ, M. M. Hispanidad e Hispanismo para profesores brasileños de Español. XI Congreso Brasileño de Profesores de Español, 2007, Salvador. Actas del XI Congreso Brasileño de Profesores de Español. São Paulo: Librería Española e Hispanoamericana - Casa del Lector, p. 2-8. Disponível em: www.educacion.es/exterior/br/ es/publicaciones/XI_congreso.pdf. Acesso 26/01/2012.

HEYMANN, L. (2007): O devoir de mémoire na França contemporânea: entre memória, história, legislação e direitos. In: Direitos e cidadania-memória, política e cultura. Rio de Janeiro: FGV, 2007, p. $15-43$.

JULIÁ, S. Vieja nación, fiesta imperial. Jornal El País, 19-7-1990. Disponível em: http://elpais.com/diario/1990/07/19/internacional/648338411_850215.html. Acesso 08/04/2012.

KARIM, T. M. Significação - Da História ao nome Israel e Palestina na Folha de S. Paulo. In: Sociedade e Discurso. Campinas: Pontes; Cáceres, MT: Unemat, 2001.

MAINGUENEAU, Dominique. Gênese dos discursos. SP: Parábola, 2008.

TATEISHI, H. Estado-nación y fiesta nacional. Oralità e Memoria, a cura di Joan Armanguéi Herrero, Cagliari: Arxiu de Tradicions, p. 5971, 2005. Disponível em: http://www7a.biglobe.ne.jp/ hirotate/ hiro-es/art-hiro/hiro-4.htm. Acesso 25/06/2012. 